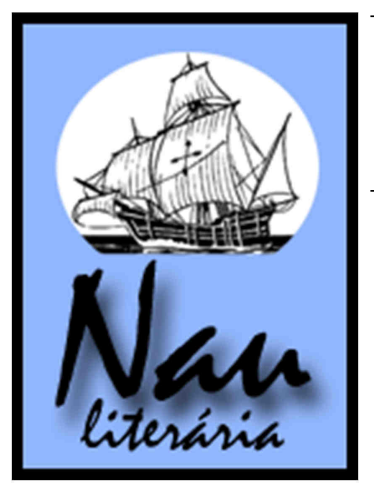

\title{
Interações poéticas entre Sophia de Mello BreynerAndresen e Lya Luft
}

\section{Marlene Rodrigues Brandolt}

\begin{abstract}
Resumo: Este trabalho desenvolve algumas interações poéticas atribuídas às aproximações entre Navegações, de Sophia de Mello BreynerAndresen, e $O$ rio do meio, de Lya Luft. A perspectiva adotada inclui uma abordagem literária feminista baseada na perspectiva de Simone Pereira Schmidt e Lúcia Helena Vianna, entre outras, intensificada pela percepção social e histórica das artistas em análise. A novidade fica por conta do diálogo entre narrativas do século XX que se oferecem por meio de uma travessia da condição humana, conectadas à recepção de Paul Ricouer e ao comparatismo de George Steiner.
\end{abstract}

Palavras-chave: Aproximações; Poéticas; Recepção; Comparatismo.

\begin{abstract}
This paper develops some poetry interactions attributed to approaches between Navegações, by Sophia de Mello Breyner Andresen, and $O$ rio do meio, by Lya Luft. The adopted perspective includes a feminist literary approach based, among others, on the perspective of Simone Pereira Schmidt and Lúcia Helena Vianna, intensified by their social and historical perceptions. The novelty is the dialogue between the narratives of the $\mathrm{XX}$ century that are offered through a journey of the human condition, connected to the reception of Paul Ricouer and to George Steiner's comparatism.
\end{abstract}

Keywords: Approaches; Poetics; Reception; Comparatism.

... o prazer de habitar a língua do outro é compensado pelo prazer de receber em casa, na acolhida de sua própria morada, a palavra do estrangeiro.

Ricoeur

Este ensaio consiste em um estudo comparativo entre as obras Navegações (1996, segunda edição), da poeta portuguesa Sophia de Mello Breyner Andresen, e $O$ rio do meio (1996, primeira edição), da brasileira Lya Luft, como um recurso de exploração entre as poéticas escolhidas em seus múltiplos encadeamentos, oferecido sobretudo pela crítica feminista. Levo em conta a dimensão poética feminista que se "apercebe [...] da necessidade de rejeitar os modelos impostos pelo colonialismo" (SCHMIDT, 2011, p. 27). Ainda que as autoras sejam oriundas de continentes colonizados, elas mantêm perfis de uma classe social alta. Desse território, comprometidas com um literário capaz de criticar a condição subalternizada do outro, desafiam normas historicamente localizadas, aplicadas ao homem e à mulher, que devem, nos espaços de teorização, da interpretação e das intervenções sociais, assumir a capacidade de independência e de bem-estar social em pé de igualdade.

\footnotetext{
* Doutoranda em Literatura (linha de pesquisa - Literatura e Mulher) pela UFSC.
} 
Decorrem daí textos poéticos que agregam às suas virtualidades o mundo na plenitude de significação histórica. Por escolher as escrituras de Sophia e Lya, permito-me uma concentração maior para delinear considerações relacionadas a uma experiência

poética que se configura como feminista, além de feminina, [...] obrigatoriamente comprometida com a consciência do sujeito-mulher sobre si mesma e sobre seu papel na história cultural em cujo cenário conquistou o direito de figurar como protagonista, atriz em cena aberta para o mundo. (VIANNA, 2004, p. 154)

Por tal viés, Navegações e O rio do meio em sua unidade indivisível, articulada a tendências atuais, indagadoras da natureza do texto artístico, em suas coordenadas tanto históricas quanto estéticas e comunicativas, fazem parte do

conjunto de obras escritas por mulheres na literatura [...], principalmente a partir da metade do século passado, [que] revela a vitalidade do corpus produzido e o modo pelo qual as mulheres se colocam perante a produção e a reprodução simbólicas (VIANNA, 204, p. 154).

Inscrevo, então, por meio de um conjunto de interações, as literaturas de Sophia de Mello Breyner Andresen e de Lya Luft como constituintes de uma poética submetida à tarefa artística que advém do universo rico de emoções e de vivências representado, em especial, pelo mar, pelo rio e pelo plano da própria condição da arte, que se encontram nas práticas e nos significados de travessia que ambas expressam. Se Lya "segue o rio do meio" (LUFT, 1996, p. 149), Sophia atravessa o rio para chegar a Lisboa, a cidade que se abre "como se do seu nome nascesse" (ANDRESEN, 1996, p. 9), para dali dar continuidade à trajetória de vida. $\mathrm{O}$ rio adquire nas produções de uma e de outra o sentido de passagem, para simbolizar a continuidade da construção do ser no mundo em constante mudança, ao que diz Lya Luft: "Isso somos" (1996, p. 149). Para tanto, a poética dessas artistas faz uma aliança entre o eu poético e a realidade. Isso porque ambas trazem para perto do leitor ${ }^{1}$ narrativas de histórias oficiais, considerando, de forma especial, a marca das navegações lusitanas em Sophia de Mello Breyner Andresen e os sinais de uma postura feminista contemporânea em Lya Luft.

Procede da conjuntura delineada acima um movimento, por vezes, de desapropriação de si mesmas, "em temas que se repetem, perguntas que se perpetuam; inquietações [que] coincidem entre o escritor e seus leitores, entre quem dá algum depoimento e quem assiste" (LUFT, 1996, p. 13). Essas palavras de Lya Luft traduzem uma das maneiras de como é possível perceber o envolvimento de ambas as autoras com o mundo do texto e com as ocorrências de vida que o rodeiam.

\footnotetext{
${ }^{1}$ Para uma leitura mais fluente, o termo leitor será, na maioria das vezes, referido no masculino, tendo em conta a diversidade de gênero.
} 
Incluo Sophia de Mello Breyner Andresen e Lya Luft por considerar que suas poéticas permitem um estudo comparativo entre elas, pela "mais simples manifestação de preferência" (STEINER, 2001, p. 152). É com esse modo de ler, o qual remete ao comparatismo, que posso revisitar essas mulheres as quais transitam pelo sistema literário, situadas, de algum modo, no local da poética feminista, compreendido por meio das palavras de Simone Pereira Schmidt:

como uma arena [...] para onde convergem os discursos de dentro e também de fora do espaço acadêmico, onde o político e o estético negociam sentidos, onde diferentes campos de saber reivindicam sua especificidade, e onde, enfim, vozes marcadas por diferenças geográficas [...] convivem, dialogam [...] e se intersectam, acentuando-se reciprocamente, em variações que muitas vezes nos escapam. (SCHMIDT, 2004, p. 17)

Na trilha de Schmidt, procuro entender a escrita da mulher como uma prática de ler e interpretar o mundo, subsídios com os quais Sophia e Lya produzem os discursos. Mulheres de seu tempo, elas interferem nos contextos em que atuam com ponderações acerca da fragilidade das relações humanas, bem como da fragmentação da realidade existente em suas obras.

Com Paul Ricoeur, a presente análise é voltada às contribuições do ponto de vista da recepção que se abre a muitas possibilidades de releituras, como a de "preservar a distância na proximidade” (RICOEUR, 2011, p. 56). Vale dizer que Ricoeur, em Sobre a tradução (2001), mantém-se atento à interpretação do leitor que resulta de um saber construído pelo conjunto de olhares, privilegiando quem lê no contexto da recepção do texto. Ressalta sobremaneira, na obra referida, o papel desse sujeito que é constantemente mencionado ao longo das suas explanações voltadas, em particular, ao "leitor em seu desejo de apropriação" (RICOEUR, 2011, p. 65). Seguindo o pensamento de Ricoeur, o texto é inseparável da recepção do leitor, uma vez que ele mesmo ajuda a tecer novos significados, gerando, por sua vez, uma série sucessiva de experiências narrativas que se prolongam com "o olhar [...] a desocultação, o descobrimento" (ANDRESEN, 1996, p. 8).

Tomo a visão de Paul Ricoeur de que é preciso superar o que "inibe antes mesmo de atacar a obra" (RICOEUR, 2011, p. 23), para cuidar, no ato de "hospitalidade", evitar eliminar distâncias "próprias a um meio, uma classe, um grupo, até mesmo um círculo secreto" (op. cit., p. 52). Para tanto, estabeleço um diálogo entre vozes marcadas por diferenças geográficas, teóricas e de gêneros literários que, neste estudo, "convivem, dialogam, disputam e se intersectam, acentuando-se reciprocamente, em variações que muitas vezes nos escapam" (SCHMIDT, 2004, p. 17). 
Ao considerar a palavra "hospitalidade" na acepção em que a usa Paul Ricoeur, fico atenta, em primeiro momento, ao lugar do estrangeiro, espaço concedido a Sophia de Mello Breyner Andresen, que me instiga a entender a sua construção estética fora do âmbito brasileiro. Segundo instante é assinalado por minha condição de leitora, em que tento apropriar-me das percepções poéticas presentes nos poemas de Navegações e na prosa de $O$ rio do meio.

Registro que as obras elencadas priorizam mundos feitos de verdades e de ilusões imagéticas, que acompanham e intervêm no conhecimento humano, mudando "a luz a sombra a cor" (ANDRESEN, 1996, p. 33). Por tal direção, o sistema comunicativo das obras é feito em correspondência com os princípios de uma poética que mobiliza a literatura de Sophia e Lya, aqui mediada pelo "seu longo luzir de azul e rio" (ANDRESEN, 1996, p. 9).

Considero então a importância de que autor e receptor se coloquem como sujeitos no estudo entre textos, como possibilidade de o leitor experimentar os vários mundos que lhe são propostos. Aqui a ideia de Ricoeur é apreendida como referência para assumir uma "leitura crítica" atribuída às equivalências entre Navegações e $O$ rio do meio. Tomo a equivalência, como modo de viabilizar, em circunstâncias interpretativas, o diálogo com as estéticas das autoras. Equivalência entendida como "presumida, prevista”, uma vez que, segundo Ricoeur, é preciso deixar de lado o desejo pela perfeição e substituí-la por uma interpretação adequada. Portanto, reporto-me ao que ele estabelece em relação à tradução, para pensar esta leitura interpretativa que também se constrói, de algum modo, à maneira de um processo tradutório.

Para tanto, procuro descobrir "o silêncio entre as palavras" (RICOEUR, 2011, p. 69), incluindo as similaridades entre os diálogos das escritoras, para levar em conta que "não terminamos nunca de nos explicar, de nos explicar com as palavras e as frases, de nos explicar a outrem que não vê as coisas sob o mesmo ângulo que nós" (op. cit., p. 53). Autorizo-me a dizer que o mar e a água metaforizam a constante busca do ser humano pela vida, para "Viver a inteireza do possível” (ANDRESEN, 1996, p. 15). As obras em estudo são dirigidas por esse sentimento e pelo parentesco cultural luso-brasileiro que norteiam a construção de Navegações e de $O$ rio do meio.

Para ambas, a escrita poética compreende o olhar metafórico como desencadeador do colóquio entre autor, mundo e leitor vislumbrado pelo exercício do pensamento simbólico. Este deriva do próprio ato criativo e interage com a história oficial que segue a "rota do oiro [...] em praias baloiçadas por coqueiros" (ANDRESEN, 1996, p. 24). Navegações e O rio do meio têm propostas e gêneros diferentes, com linguagens diversas, as quais se aproximam, principalmente, como "ficções [...] que separam o sonhado e o real" (LUFT, 1996, p. 17). 
Com efeito, a arte dessas autoras pode ser vista como manifestação comunicativa da historicidade que envolve leitor-obra-autor, sem perder de vista o literário com base em uma poética "vital em que nos lançamos em direção aos outros, abertas às muitas possibilidades [...] de interação" (SCHMIDT, 2004, p. 19). Por entre as narrativas, as poetas caminham atraídas pela luz, pelas sombras que fazem parte de suas aspirações, ao que atribui, por exemplo, Sophia: "Dos homens nus e negros contarei/ E de como não havendo já conosco" (ANDRESEN, 1996, p. 27).

Os sentidos em Navegações e em $O$ rio do meio surgem de diferentes referenciais literários sobre os quais as autoras debruçam-se para recriar os textos, "dialogando com o fascinante - às vezes trevoso - que espreita sobre nosso ombro nas atividades mais cotidianas" (LUFT, 1996, p. 13). Assim, as obras refletem a história oficial, bem como a "Intertextualidade que significa, às vezes retomada, transformação, refutação de empregos anteriores por autores vindos da mesma tradição de pensamento ou de tradições adversas" (RICOEUR, 2011, p. 25), como surge em Sophia, o poeta Luís Vaz de Camões e, em Lya, nas epígrafes, a poeta Cecília Meireles, entre outros poetas.

As autoras retomam, com um novo sentido e com outro ritmo, outros artistas que o literário permite em sua constituição própria de uma "dança de máscaras e desvendamentos" (LUFT, 1996, p. 14). Ao mesmo tempo, preservam a "possibilidade sempre disponível de falar sobre a linguagem, de colocá-la a distância, e assim, de tratar [a] própria língua como uma língua entre outras" (RICOEUR, 2011, p. 36).

Similar à viagem entre textos literários, existe a histórica que se aproxima das tradições, como no caso de Sophia, que se refere aos descobrimentos dos navegadores lusitanos, para transformar a sua poesia pessoal, teatral e narrativa:

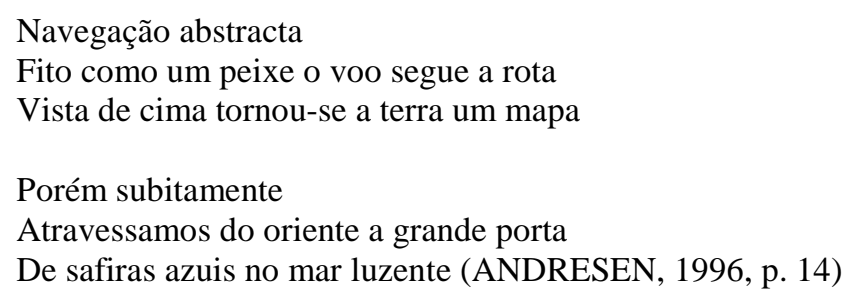

As artistas expõem suas perspectivas poéticas ao redescrever a realidade, unindo os tempos e os lugares que exercem influência sobre o leitor, que passa a partilhar de "muitas novas indagações" (LUFT, 1996, p. 15). Pela ordem do literário, discutem a relação com o sujeito e o mundo por meio da história oficial e do sistema literário. Provocam no leitor o desejo de questionar o real e traduzir "os contextos escondidos e o que chamamos conotações, 
as quais nem sempre são intelectuais, mas afetivas [...] uma margem do não dito, percorrida por todas as figuras do escondido" (RICOEUR, 2011, p. 52).

Por tal perspectiva, o processo de comunicação entre Sophia e Lya pressupõe as relações simbólicas e literais ao longo de suas escritas. Por esse motivo a presente interpretação não se restringe ao confronto de tensões resultante das relações desiguais de gênero, de culturas e ideias, antes, prevê a compreensão do outro, fundamentada no reconhecimento de símbolos que ocupam a existência humana. Ao trabalharem a noção de ser-no-mundo, as escritoras ultrapassam os limites da linguagem da arte, para buscar igualmente a relação com a realidade, em discursos que assumem interioridade e autonomia, para atrever-se à "aventura a mais incrível” (ANDRESEN, 1996, p. 15).

Tal procedimento interpretativo possibilita articular a visão poética das autoras como tradução dos sentidos conformados pelo comparatismo literário que se constrói pela diversidade. Isso remete ao desenho da torre de Babel: "Cada uma das janelas desse prédio das línguas abre-se para uma paisagem diferente em uma época diferente, para uma segmentação do espectro da realidade percebida e classificada de maneira também diferente" (STEINER, 2001, p. 159).

A passagem sobre Babel permite-me aproximar Ricoeur e Steiner com suas diversidades, no que diz respeito à tarefa da tradução. Em Sobre a tradução (RICOEUR, 2011, p. 55), no capítulo "O paradigma da tradução", o autor discute o "extremismo de Steiner", ligado "ao hermetismo [...], para dizer tudo, à não comunicação". Contrariando essa visão fechada, Ricoeur considera que "Os textos, esses encadeamentos de frases que, como a palavra indica, são texturas que tecem o discurso em sequências [...] na medida em que aprendemos que se pode contar de outro modo variando a configuração da intriga, da fábula!" (op. cit., p. 53).

Ambos os críticos, mesmo que percebam a atividade tradutória de maneira diferente, avizinham-se "como outro", na condição também de leitores que interpretam e atualizam as suas proposições de mundo e convidam o leitor a perceber uma nova explanação. Até porque, em “O que é Literatura Comparada?”, George Steiner (2001, p. 158) tenta responder que todo ato de recepção em linguagem, em arte e música é um ato comparativo, o qual se "deleita [...] com essa diversidade".

A orientação de Steiner às pesquisas comparatistas relacionadas à produção e à recepção de sentidos textuais envolve inscrições de sujeitos literários no entremeio de fronteiras que acontecem como encontro de vozes e de imagens, para, de certo modo, evitar "o isolamento e a arrogância nacionalista [como formas] que levam à ruína brutal" 
(STEINER, 2001, p. 155). Por conseguinte, os versos andresianos e a prosa luftiana apresentam-se, apesar das diferenças de gêneros, como complementos à existência de uma e outra, uma vez que oferecem ao leitor "a capacidade e a liberdade para perceber, articular e modificar o mundo em que vive" (op. cit., p. 158).

Aqui abro parênteses para traçar, em linhas gerais, o perfil de Sophia de Mello Breyner Andresen, escritora portuguesa, natural do Porto. Estudou filologia clássica na Universidade de Lisboa, cidade que escolheu para viver. Mãe de cinco filhos, configurava em sua escrita o ambiente da sua infância, sobretudo nos livros para crianças. Escreveu poemas, contos, ensaios e traduções de Dante, Shakespeare e Eurípedes. A sua obra literária encontrase parcialmente traduzida na França, Itália e nos Estados Unidos da América. Em 1994 recebeu o Prêmio Vida Literária, da Associação Portuguesa de Escritores, e no ano seguinte, o Prêmio Petrarca, da Associação de Editores Italianos.

Ao pensar a literatura portuguesa de Sophia emerge um componente decisivo do comparativismo literário: "a abertura promovida por este debate com o estrangeiro [...] abrenos o pensamento e combate nosso provincianismo narcisista" (SCHMIDT, 2008, p. 118). Nela, a palavra assume-se como um agente de transfiguração da relação com a natureza, com as sensações marítimas, onde o Eu reencontra, por meio de palavras mágicas e reais, a aliança com os indivíduos de todos os tempos, dialogando consigo e com o outro:

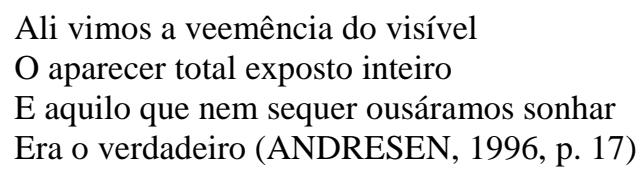

A poeta portuguesa, com a visão de que os homens avancem para mudanças, situa um panorama literário radicado no compromisso social e político com o mundo e com o seu tempo,

onde ainda é visível o espanto do olhar inicial, o deslumbramento perante a diferença, perante a multiplicidade do real, a veemência do real mais belo que o imaginado, o maravilhamento perante os coqueiros, os elefantes, as ilhas [...] a revelação de um outro rosto do humano e do sagrado. (ANDRESEN, 1996, p. 8)

Em síntese, Navegações compreende três partes em torno da temática dos descobrimentos marítimos, reatualizados em uma viagem de Sophia a Macau, "primeiro encontro com o Oriente" (ANDRESEN, 1996, p. 7), quando a poeta é convidada pelo Conselho da Revolução, em 1977, para tomar parte na celebração do Dia de Camões. As divisões, na exposição dos poemas, ligam-se pelo olhar de encantamento, memória temporal de um falar poético que recupera os momentos de "elaboradas estranhezas" (op. cit., p. 33). A 
primeira parte do livro é dedicada a Lisboa (p. 9), local de onde saíram os portugueses para conquistar o mundo durante os séculos XV e XVI, em especial, para chegar às terras brasileiras e deixar aqui a fonte que contribuiria marcantemente para os primeiros passos de nossa literatura até sua independência.

De "Lisboa", poema de abertura da obra, a poeta percorre "As ilhas" que surgiram luminosas "De um azul tão puro e tão violento/ Que excedia o fulgor do firmamento/ Navegado por garças milagrosas" (ANDRESEN, 1996, p. 13). O último capítulo de Navegações segue a rota da "Deriva", que neste ensaio toma o sentido de origem das descobertas de navegadores que regressavam da viagem por mares nunca antes navegados, "Sob o clamor de um sol inabitável" (op. cit., p. 18). Ainda para justificar a opção pela definição da palavra deriva, cito o poema XV, em que a poeta retoma a cidade de Lisboa:

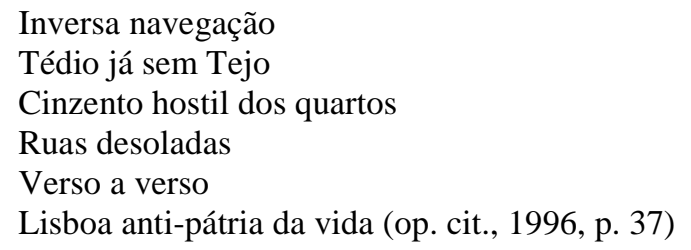

Similarmente, Lya, no último capítulo, "Deus é sutil", em O rio do meio, volta também à origem, no caso, da criação do homem, ao fazer alusão aos mistérios humanos, na figura de Deus que "Entre sótãos e porões segue o rio do meio" (LUFT, 1996, p. 149).

Cuido para não referenciar apenas o que vem de fora do território brasileiro quase "sempre tomado como referência" (SCHMIDT, 2008, p. 118) e transponho para este ensaio a obra $O$ rio do meio, de Lya Luft. Aprecio-a como marca da transitoriedade de um eu que acontece por meio de "interrogações: sobre as relações pessoais, a prodigiosa vida, o limite entre a fatalidade [...]" (LUFT, 1996, p. 16).

Com sensibilidade alicerçada por uma visão política e feminista, Lya, gaúcha de Santa Cruz do Sul, iniciou sua carreira há mais de vinte anos como tradutora de obras literárias em alemão e inglês, e continua até hoje, traduzindo para o português Virginia Wolf, Doris Lessing, Günter Grass e Botho Strauss. Aos 40 anos, após publicar dois livros de poemas e um de crônicas, lançou-se como romancista com As parceiras (1986), em um período em que as "mulheres e suas reivindicações haviam virado assunto digno de atenção no país", e no qual "Predomina o tom do testemunho e do depoimento" (SCHMIDT, 2000, p. 79-80). Nessa obra, dá voz às mulheres, em particular, denunciando a violência praticada contra elas.

Faço um recorte temporal na releitura das produções literárias de Lya, para situar $O$ rio do meio, publicado em 1996. Obra de sete capítulos, em que a narradora explica que 
"Fazer ficção é vagar à beira do poço interior observando os vultos no fundo, misturados com minha imagem refletida na superfície" (LUFT, 1996, p. 13), recurso metalinguístico que instiga o leitor a outros mecanismos do fazer ficcional. Retoma no conjunto da obra o intimismo com tons pessoais e sob o ponto de vista feminista, para falar de infância, madureza, mulheres e destino; homens e seus sonhos; vida e mortes; ficções, realidade e Deus.

Sem isolar a história de submissão das mulheres, $O$ rio do meio mostra uma consciência altamente positiva da participação da mulher no contexto literário e nacional: "Saiu a campo para preparar-se" (LUFT, 1996, p. 97). Assim, Lya Luft abandona, em parte, as normas impostas por práticas sociais e, com uma poética existencial, pode "atuar junto ao feminismo com grandes contribuições para ampliar seu campo de atuação e suas perspectivas, além de trazer [para o contexto da crítica] um vigor novo" (SCHMIDT, 2008, p. 121). Nesse sentido, ela consegue desconstruir o cânone literário, onde "A maior parte das mulheres marcantes na ficção foi inventada e escrita por homens; agora nós tentamos descobrir e expor o nosso perfil" (LUFT, 1996, p. 91).

Pelo perfil das escritoras Sophia e Lya, como mulheres engajadas socialmente, e pelos traços de uma poética em que as diferenças "somaram-se, não se descaracterizando" (LUFT, 1996, p. 89), é possível dizer que ambas inscrevem o feminismo, por meio de uma escritura que procura desestabilizar o que tem, durante séculos, servido à tradição patriarcal, sempre em oposição à experiência da mulher: frágil, passiva e incapacitada intelectualmente.

Em contrapartida, o eu em Navegações e em $O$ rio do meio surge como expressão de autoras que recriam a si mesmas pela rememoração de outras existências poéticas historicamente reconhecidas, conforme ilustram os versos de Sophia Andresen:

\footnotetext{
Eu vos direi a nudez recém-criada

A esquiva doçura a leve rapidez

De homens ainda cor de barro que julgaram

Sermos seus antigos deuses tutelares

Que regressavam (ANDRESEN, 1996, p. 29)
}

Tais obras, escrituras da segunda metade do século XX, oferecem possibilidades de comparações que contribuem para "somar aquilo que temos como patrimônio da melhor tradição feminista [com] o mundo das diferenças e possibilidades", o que enriquece ainda mais a experiência e a prática de uma escritura construída por mulheres, conforme SCHIMIDT (2008, p. 121).

Nos interstícios do poético, as vozes das autoras em análise misturam-se ao rumor do mar e do rio e marcam suas percepções de sujeitos que se constituem como "um modo de 
pensar a sociedade de um raro alcance interpretativo, operando e fazendo interagir categorias tão eficazes quanto distintas de análises de relações sociais” (SCHMIDT, 2008, p. 87). É mediante a arte que Sophia e Lya constituem estéticas, enquanto sujeitos de suas vidas, de suas histórias e, ao mesmo tempo, das narrativas lidas e reescritas por elas. Reproduzem uma arte cuja elaboração artística envolve a superação de "um discurso colonial e paternalista", ao estabelecerem “intervenção diária na arena das disputas de significado no campo do saber, [o que] consiste em formular novas interpretações dos novos e velhos discursos produzidos na cultura" (SCHMIDT, 2004, p. 17).

As poéticas aqui retomadas fazem "aparecer, na fricção das duas imagens, as diferenças [...] históricas" (SCHIMDT, 2009, p. 803) e conseguem atualizar as dores próprias da vida, colocando-se no centro das discussões ficcionais abertas às muitas possibilidades de interações sociais e culturais "Por isso, quem sabe, mais inclinadas à contemplação [de onde] talvez ruminemos o que não entendemos de nós, que tanto nos espanta - e nos maravilha sempre (LUFT, 1996, p. 78).

Sophia morreu em 2004 e suas palavras ecoam entre acadêmicos, público-não profissional e artistas. Lya transita entre o público contemporâneo com sua força de escritora, escrevendo na revista Veja e ministrando palestras em instituições de ensino, bem como em diferentes centros comunitários, e suas palavras contidas de sensibilidade encantam a quem escuta. Assim, faço um contorno de duas mulheres que assinalam uma estética literária multiforme, contemplando o modo do público-leitor "de pensar, de amar, de desejar, agir e perceber o mundo" (COELHO, 1986, p. 30).

Apresento, com as obras de Sophia e de Lya, um diálogo construído por um movimento de introspecção, possibilitado pelas narrativas que são feitas por elas, sobre elas, bem como sobre o leitor - "um interlocutor ainda que silencioso" (LUFT, 1996, p. 16) -, o qual partilha das histórias e confere a essas assimilações possibilidades de uma nova tessitura. Isso acontece porque são escritoras articuladas a uma interpretação produzida por linhas emblemáticas que se ligam às narrativas da vida cotidiana, bem como a vozes de outros artistas.

As equivalências entre suas obras podem ser possíveis na medida em que ambas discorrem conhecimentos, emoções e pretensões que se unificam na formação de cada ser. São poesia e prosa que se compõem em torno de um eixo literário como rede de interações trabalhadas "na construção de lugares outros, não centralizados, de saber e poder" (SCHMIDT, 2004, p. 21). 
Com efeito, as poetas permitem a construção e reconstrução do "eu" e de demais eus que se observam e que podem "escolher alguns fios, um tom, a espessura certa, ou até colaborar no desenho" (LUFT, 1996, p. 105) de uma escritura de ordem histórica e ficcional. É aí que residem algumas das características comuns entre Sophia e Lya, quando o eu-lírico de suas obras se dilui em passagens daquilo que elas descrevem, pela capacidade de representar por palavras fatos que aconteceram.

Por conseguinte, as aproximações, no espaço da produção literária de Navegações e de $O$ rio do meio, acontecem por meio de manifestações de seres que se reconhecem e fazem a travessia para uma nova ordem de experimentar o mundo na direção dos sobressaltos de viver na sua integridade. É preciso apreendê-las como estéticas em construção dialógica, em que as contradições sociais e individuais são artifícios, quase sempre, utilizados pelas duas narrativas, como acontece nos versos de Sophia:

Lisboa com seu nome de ser e de não-ser

Com seus meandros de espanto insônia e lata

E seu secreto rebrilhar de coisa de teatro

$[\ldots]$

Lisboa oscilando como uma grande barca

Lisboa cruelmente construída ao longo da sua própria ausência (ANDRESEN, 1996, p. 9).

e na narrativa de Lya:

lia uma página de seu texto interior que fala de chama, vento, ilha, coisas muito mais reais do que uma sala, pessoas e carros. Fazia isso como muitas mulheres certamente poderiam fazer, mas se contêm para que outros, percebendo, não se perturbem (LUFT, 1996, p. 145).

É válido considerar que o estudo comparado entre elementos equivalentes é, em particular, um modo de interpretar múltiplos universos, dos quais as obras mencionadas e seus procedimentos literários adquirem vários tons, previstos pela ordem do real/irreal. Tal deslocamento de fronteiras inscreve-se por meio de um jogo comparativo, feito acerca do potencial das literaturas de Sophia e de Lya, que se afirmam, de certa maneira, a partir do ponto de vista da arte, no qual a natureza ilusória do real é elemento constituinte desse espaço.

As obras Navegações e $O$ rio do meio podem ser submetidas a inúmeras e diversas propostas por outros acadêmicos, os quais devem trazer novas contribuições no que diz respeito às sobreposições entre elas. Tal inscrição é propícia pela aproximação entre o território português e brasileiro pela língua e pela forma de acolhimento a outras culturas, características particulares do povo luso-brasileiro. Portanto, a leitura proposta, ao aproximar as obras de Sophia e de Lya, aceita, principalmente, que o sistema literário brasileiro não se 
sinta "ameaçado de [se] fechar na amargura de um monólogo, a sós com nossos livros" (RICOEUR, 2011, p. 55).

Para consolidar o presente estudo, trilhei um caminho que diz respeito às percepções do leitor, pautado por escrituras feministas que se envolvem com a pluralidade humana, "ladeando inicialmente o indizível" (RICOEUR, 2011, p. 55). De maneira geral, direcionei meu olhar em sintonia com os diálogos entre poetas e teóricos, a partir dos quais pude reter uma gama de experiências marcadas pelo pluralismo que deve apontar para outras conversações, outros desdobramentos comparatistas, em diferentes contextos e tempos. Sei que as vozes das artistas e críticos que me auxiliaram a entender a localização da mulher no imaginário sobretudo nos continentes colonizados, precisam seguir outros caminhos além das interpretações encaminhadas.

Restam outros modos de ler que podem ser ampliados em futuros trabalhos acadêmicos, e aqui cito alguns que as estéticas de Sophia e de Lya propiciam focalizar: interferências nas manifestações das diferentes artes; diálogo com a cultura digital contemporânea e a capacidade tradutora de um mundo marcado pelo deslocamento da história literária feminista que existiu sempre de diversas maneiras e em diferentes sentidos em lugares outros.

Sophia e Lya comportam a discussão de valores estéticos que conseguem exercer, no receptor, representações figuradas e sentimentos, determinados por ações orientadas pelo fantasioso e pela própria experiência de vida das escritoras. Portanto, Navegações e $O$ rio do meio, por não se reduzirem a um falar ou a uma ficção, tornam disponíveis elementos para melhor abrangência da expressão poética e do conhecimento humano ao longo do tempo.

\section{Referências}

ANDRESEN, Sophia de Mello Breyner. Navegações. Lisboa: Caminho, 1996.

COELHO, Nelly Novaes. Literatura \& linguagem: a obra literária e a expressão lingüística. São Paulo: Quíron, 1986.

LIMA, Luiz Costa (Coord. e Trad.). Teoria literária e suas fontes. Rio de Janeiro: Civilização Brasileira, 2002.

LUFT, Lya. As parceiras. 5. ed. São Paulo: Siciliano, 1986.

LUFT, Lya. O rio do meio. São Paulo: Mandarim, 1996. 
RICOEUR, Paul. Teoria da interpretação: o discurso e o excesso de significação. Lisboa: Edições 70, 1976.

RICOEUR, Paul. Sobre a tradução. Belo Horizonte: Ed. da UFMG, 2011.

SALLES, Walter. Paul Ricoeur e a hermenêutica de si no espelho das palavras. Disponível em: <www.scielo.org.ve/scielo.php?pid=S1315-52162009000400004>. Acesso em: 10 fev. 2012.

SCHMIDT, Simone Pereira. Cravo, canela, bala e favela. Estudos Feministas, Florianópolis, v. 17, n. 3, p. 799-817, set.-dez. 2009. Disponível em: <https://periodicos.ufsc.br/index.php/ ref/article/view/13023>. Acesso em: 20 maio 2014.

SCHMIDT, Simone Pereira. O feminismo nas páginas dos jornais: revisitando o Brasil dos anos 70 aos 90. Estudos Feministas, v. 8, n. 2, 2000. Disponível em: <https://periodicos.ufsc.br/index.php/ref/ article/view/11921>. Acesso em 12 jan 2012.

SCHMIDT, Simone Pereira. Como e por que somos feministas. Estudos Feministas, Florianópolis, v. 12, n. especial, p. 17-22, set.-dez. 2004. Disponível em: <www.periodicos.ufsc.br/index.php/ref/ article/view/10220/9443>. Acesso em: 12 dez 2011.

SCHMIDT, Simone Pereira. A seção Debates em revista: práticas feministas de tradução. Estudos Feministas, Florianópolis, v. 16, n. 1, p. 288, jan.-abr. 2008. Disponível em: <http://www.scielo.br/pdf/ref/ v16n1/a11v16n1.pdf>. Acesso em: $10 \mathrm{dez} 2012$.

STEINER, George. O que é literatura comparada? In: Nenhuma paixão desperdiçada. Rio de Janeiro: Record, 2001.

STEINER, George. O leitor incomum. Trad. de Maria Alice Máximo. Excerto do primeiro capítulo de Nenhuma paixão desperdiçada (Rio de Janeiro: Record, 2001). Disponível em: <http://filosofia.paginas.ufsc.br/files/2013/04/George-Steiner-O-Leitor-Incomum1.pdf>. Acesso em: 23 maio 2014.

VIANNA, Lúcia Helena. Poética feminista: poética da memória. Florianópolis: Ed. Mulheres, 2004. 